\title{
A STOCHASTIC FRONTIER APPROACH FOR MEASURING TECHNICAL EFFICIENCY OF SMALL-SCALE IMPROVED SALT PRODUCTION IN GUINEA
}

\author{
${ }^{1}$ Boubacar Siddighi Balde, ${ }^{2}$ Hajime Kobayashi, ${ }^{2}$ Makoto Nohmi, \\ ${ }^{3}$ Akira Ishida, ${ }^{2}$ Ichizen Matsumura, ${ }^{4}$ Mohamed Esham and ${ }^{1}$ Emmanuel Tolno \\ ${ }^{1}$ The United Graduate School of Agricultural Sciences, Tottori University, Tottori, Japan \\ ${ }^{2}$ Faculty of Agriculture, Tottori University, Tottori, Japan \\ ${ }^{3}$ Faculty of Life and Environmental Science, Shimane University, Matsue, Japan \\ ${ }^{4}$ Faculty of Agricultural Sciences, Sabaragamuwa University of Sri Lanka, Sri Lanka
}

Received 2014-02-12; Revised 2014-03-18; Accepted 2014-05-14

\begin{abstract}
Salt production is a major driving force behind the loss of mangrove in Guinea. As the traditional salt production causes increasing deforestation, the intensive exploitation of mangrove resources has now reached a critical threshold. Therefore, improved techniques using sunlight as the source of energy has been introduced as an alternative to the traditional salt production techniques which consumes a significant amount of mangrove wood. Therefore, it's of interest to examine the efficiency of the new salt production technique, in this an attempt is made to determine the technical efficiency of salt producers adopting the improved techniques by using the stochastic frontier analysis method. The study used primary data collected through a survey. A sample of 100 salt producers was interviewed during March-April 2013. However, this study considers only 65 producers using the improved salt production techniques along the Guinean coast in Koba, particularly in Balessourou district. The results revealed that labor cost and dimension of the basins contribute to enhance the performance of salt production in terms of revenue earned. Inefficiency model indicated that membership in salt producer organizations, producers' participation in activities organized by local and/or international institutions; family size and land rent significantly influenced technical inefficiency. Results also highlighted the fact that even the best producers were inefficient. The mean level of their technical efficiencies was estimated at $27 \%$, while the efficiency ranged from 0.0 to $92 \%$. In addition, the estimation of the loss due to the inefficiency occurring seasonally was significant and valued at 601,024 Guinean francs per basin. In order to improve the efficiency of salt production, this study advocates some strategies such as coating basins for minimizing the loss of salt during extraction, encouraging producers' participation in activities organized by the government and its partners and strengthening producers' organizations to enhance producer participation in salt production.
\end{abstract}

Keywords: Guinea, Improved Salt Production, Koba, Stochastic Frontier Analysis, Technical Efficiency

\section{INTRODUCTION}

According to the Guinean Ministry of Planning and Cooperation, reported by (Maadjou, 1986), an average of 9 persons consume $61.5 \mathrm{~kg}$ of salt per year, or an average of $6.8 \mathrm{~kg}$ of salt per person per year. In rural and small town areas, the average estimated value was $5 \mathrm{~kg}$ per person per year. In 2008, given that $75 \%$ of the Guinean population consumes salt produced in the mangrove area, production for domestic use of the population could be estimated at 44,325 tons per year. In addition, production of salt for livestock and various others consumption were

Corresponding Author: Boubacar Siddighi Balde, The United Graduate School of Agricultural Sciences, Tottori University, Tottori, Japan, Tel: +81-80-4264-8171 
estimated at $30 \%$ of domestic needs $(15,000$ tons per year). Based on these estimates, in 2008, the production of salt in Guinea was approximately 57,622.5 tons. The analysis of small-scale salt production techniques Traditional Salt Production (TSP), Guinean Saline (GS) and Salt Marsh (SM)) was conducted in the coastal area of Koba in Guinea.

The TSP is seasonal, practiced around four months, from February 15th to May 15th. The traditional salt production is based on evaporation under the action of heat. The salty earth is scraped and collected in the foreshore area or in a swamp drained. Collected salt crusts are gathered in the vicinity of operating sites. For the leaching stage, the collected salty earth is transferred into series of filters, which are then filled up with raw saline water. The downward seepage and infiltration of the raw saline water results in the dissolution and leaching of the crystallized salts, as brine leachate, into the receiving containers (usually a big plastic pot, hole,) placed below the filters. The set-up can be either single or multiple filters. Periodic addition of more raw saline water maintains the continuous leaching process, until the concentration of the leachate is considered not much different from the infiltrating raw saline water. Then, the leached soil material is replaced with fresh salty earth and so the leaching process can continue again. The brine obtained by filtering the salty earth is poured into the pan. Its utilization is conditioned by the usage of wood gathered from the mangrove or upland forests.

The GS requires the purchase of tarpaulin (plastic sheet) which is a significantly lower investment than purchasing cooking bowls (pans). This technique requires a short support (in-situ saline school training) and making available tarpaulins to producers in the early years. The solar salt production frees producers from buying and/or collecting firewood and lightens the drudgery (by removing the cooking stage) leading to improved productivity. Once the brine is obtained by leaching the salty earth, it is poured into the tarpaulins and evaporation is carried out by the solar energy.

The SM is practiced for around six months from November to May. The sea water is collected in reservoirs and then filtered through a series of salt basins where, via evaporation and crystallization, salt crystals are deposited. These basins are always coated by tarpaulins allowing the storage of a significant volume of seawater. Producing salt from the sea, involves channeling sea water to flow into the basins and allowing the water to evaporate using wind and solar energy. The water evaporates from successive ponds until the brine is fully concentrated and salt crystallizes on the floor of the crystallizing ponds.
The improved salt production techniques (GS and SM) have revealed the importance of the adoption of tarpaulin (plastic sheet) in terms of earned profit, access to convenient household assets and better housing conditions. An improved living condition could limit the deforestation of mangrove and upland forests. The adoption of the improved salt production techniques resulted in the minimization of the total variable cost related to the salt production, which leads to high profits (Balde et al., 2013b). Thanks to the use of tarpaulin instead of firewood, improved techniques also shorten the daily working time. This time saving on working hours has a significant impact on income generated from a secondary activity as it enables salt marsh producers to be involved in the mangrove rice production, thereby earning an additional income (Balde et al., 2013b). Salt production using these improved techniques resulted in high quality salt, which was able to fetch a premium price. Therefore, in this study, only improved salt producers are considered for the efficiency analysis. Although there have been many studies on the technical efficiency of agricultural production in West Africa (Ekunwe et al., 2008; Ogundele and Okoruwa, 2004), however, there are no studies been conducted in West Africa, particularly in Guinea on the technical efficiency of salt production.

In the above context, the role of improved salt production techniques has drawn many questions and the objective of this study is to answer these questions. Whether improved salt producers in the Guinean coastal area are efficient? How significant is the loss due to the inefficiencies? In addition to investigating the level of technical efficiency, this study also examines the factors determining the inefficiency of improved salt production industry in Guinea. A pre-requisite for enhanced efficiency is to identify the factors at the producer-level and other factors that affect the efficiency of salt production. Insights into these factors will enable the formulation of policies and strategies for enhancing salt production.

\section{MATERIALS AND METHODS}

\subsection{Study Area and Data Collection}

Koba sub-prefecture (Fig. 1b) is one of the eight subprefectures (Tamita, Lisso, CU Boffa [urban commune of Boffa], Douprou, Kolia, Tougnifili and Mankountan) of the Boffa prefecture (Fig. 1a). It is located hundred kilometers away from the Boffa prefecture, covering an area of $1,026 \mathrm{~km}^{2}$ with a total population of 52,720 inhabitants of which 27,304 are females. 


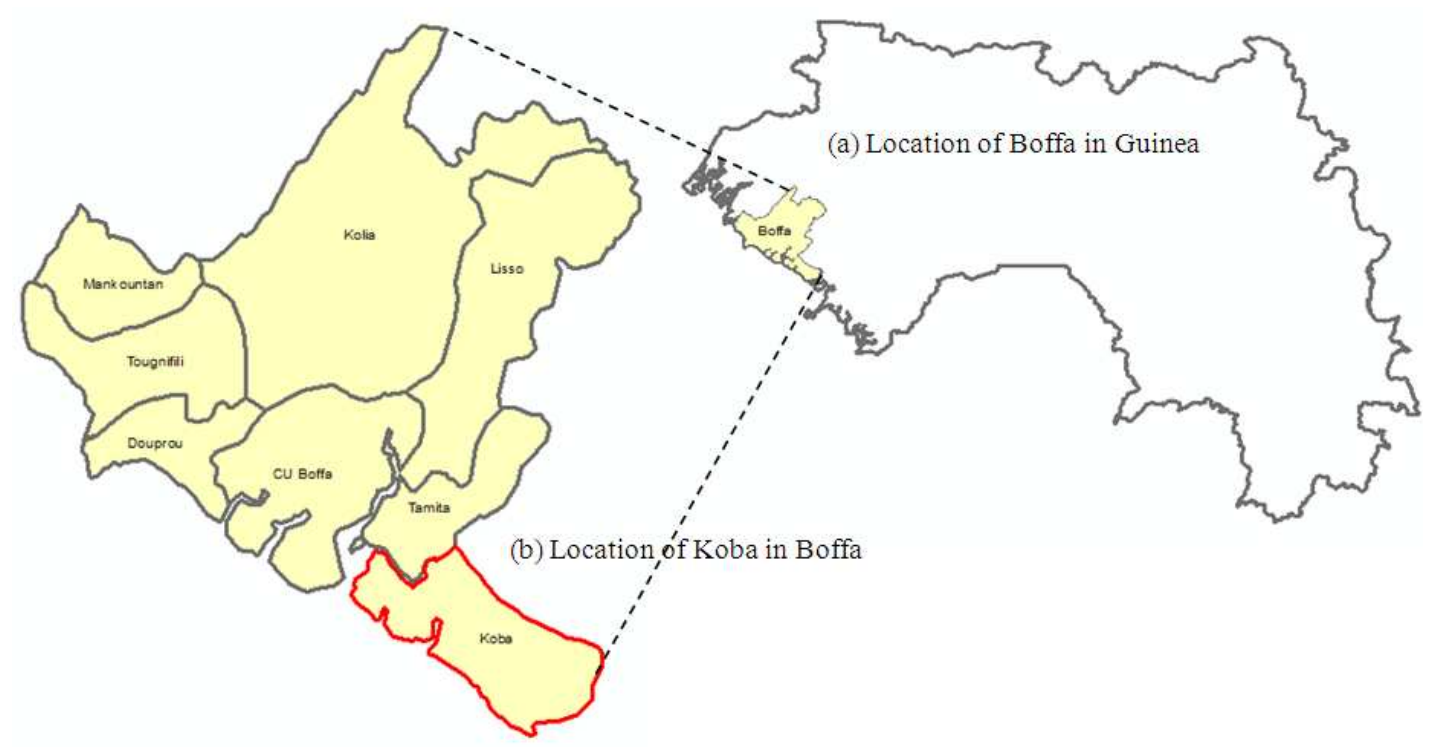

Fig. 1. Location of the study area

Koba is bordered to the North by Tanene sub-prefecture of Dubreka prefecture (Balde et al., 2013a), to the West by Mara Island in the urban commune of Boffa and to the South-East by the Atlantic Ocean. Koba is the main region in Guinea in terms of salt production and mangrove rice production. The study area is home for the agronomic research Center of Koba (CRAK) which specializes in the experimentation of mangrove and freshwater rice varieties. This area has many facilities and infrastructures compared to all other sub-prefectures throughout Guinea.

A Field survey was conducted from March to April 2013. Structured questionnaire designed to capture information related to the characteristics of salt producers, their inputs allocated to the salt industry and its output. This questionnaire was administered to 100 respondents belonging to three different groups: 35 traditional salt producers, 25 mixed salt (Guinean saline) producers and 40 salt marsh producers. However, this research focused only on improved salt producers (the last two groups).

\subsection{Empirical Analysis: Stochastic Frontier Production (SFP) and Efficiency Measurement}

Coelli (1996) had developed the software FRONTIER 4.1, which can be used to generate both the stochastic production frontier and the inefficiency model simultaneously. The FRONTIER 4.1 was widely applied in different fields of research in the past 15 years, especially in agricultural studies (Binuomote et al., 2008; Bakhsh et al., 2006; Bamiro et al., 2006; Battese and Coelli, 1995). This study applied FRONTIER 4.1 with the trans-log production function for the analysis of technical efficiency. The Stochastic Frontier Approach (Coelli et al., 1998) was used for measurement of technical efficiency. Inefficiency was defined as the distance between a producer's actual salt production value and the estimated frontier salt production value that corresponds to the state of its production technology. Output value, the revenue from salt production, in Guinean Franc (GNF) was used as the dependent variable since some previous empirical studies have used the monetary value as the dependent variable (Coelli and Battese, 1996; Aigner et al., 1977). The explanatory variables used to explain efficiency were included in the model when estimating the measures of technical efficiency. The results of the likelihood ratio-type test, used to test Cobb-Douglas against the translog, showed that Cobb-Douglas was an appropriate model for the present data. Based on Battese and Coelli (1995) and Coelli et al. (1998), the following model was used:

$$
\operatorname{In} Y_{i}=\beta_{0}+\sum_{i=1}^{x} \beta_{j} \operatorname{In} X_{i j}+v_{i}-u_{i}
$$

where, $\mathrm{Y}_{\mathrm{i}}$ is the dependent variable in the production function representing the revenue from salt production value expressed in GNF of $i^{\text {th }}$ salt producers, $X_{i j}$ is the $j^{\text {th }}$ 
input $(j=1-4)$ used by $i^{\text {th }}$ farmer. $\beta_{0}$ is intercept (constant) and $\beta_{\mathrm{j}}$ are response parameters to be estimated or elasticity corresponding to each input $(\mathrm{j}=1-4)$, including labor cost, equipment cost, dimension of basins and tarpaulin cost. $v_{i}$ and $u_{i}$ are components forming an error term $\left(\varepsilon_{\mathrm{i}}\right) . \mathrm{v}_{\mathrm{i}}$ is random variable error associated with random factors such as measurement errors and other statistical noise and exogenous factors beyond the producers' control such as natural disasters. $\mathrm{v}_{\mathrm{i}}$ is assumed to be independently and identically distributed and independent of $u_{i}$. While $u_{i}$ is non-negative random variable associated with farm's specific factors which would affect technical efficiency of salt producers. $u_{i}$ is assumed to be independently truncated-normal distribution with mean $\mu$ and variance $\delta^{2}$. Although $u_{i}$ can also have other distributions, FRONTIER 4.1 computer program used in the study can only harmonize with above assumption. The term $\mu_{\mathrm{i}}$ is defined as follows:

$$
\begin{aligned}
& \mu_{i}=\delta_{0}+\delta_{1} Z_{1 j}+\delta_{2} Z_{2 j}+\delta_{3} Z_{3 j}+\delta_{4} Z_{4 j}+\delta_{5} Z_{5 j}+ \\
& \delta_{6} Z_{6 j}+\delta_{7} Z_{7 j}+\delta_{8} Z_{8 j}+\delta_{9} Z_{9 j}+\delta_{10} Z_{10 j}+\omega_{i}
\end{aligned}
$$

where, $\mu_{\mathrm{i}}$ is inefficiency effects that could be estimated by 2 stage estimation technique in FRONTIER 4.1 spontaneously. $\delta_{0}$ is the intercept term, $\delta_{j}$ is the parameter for $\mathrm{j}^{\text {th }}$ independent variables. $\mathrm{Z}_{1 \mathrm{j}}$ is distance to the campsite $(\mathrm{km}) ; Z_{2 j}$ is land rent considered as dummy variable $(0=$ free; $1=$ rental $) ; Z_{\mathrm{aj}}$ represents age of salt producers (years). $\mathrm{Z}_{4 \mathrm{j}}$ is gender participation in salt production $(1=$ male; $0=$ female $) ; Z_{5 j}$ is educational level (schooling years); $Z_{6 j}$ is family size (persons); $Z_{7 j}$ is participation in activities conducted by local or international NGOs in the study area. $Z_{8 j}$ represents membership in salt production $(1=$ membership and $0=$ otherwise $) ; Z_{9 j}$ is unit price per salt bag in Guinean Franc (GNF). $Z_{10 j}$ is the offfarm income and remittance per family size. $\omega_{1}$ is an error term (unobservable random variable). Maximum Likelihood Estimates (MLEs) for all parameters of the stochastic frontier production (Equation 1) and inefficiency model (Equation 2) were simultaneously estimated by using the FRONTIER 4.1 computer program (Coelli, 1996). This program also presented the coefficients of variance parameters Equation 3 to 5:

$$
\begin{aligned}
& \sigma^{2}=\sigma_{v}^{2}+\sigma_{u}^{2} \\
& \gamma=\sigma_{u}^{2} / \sigma_{v}^{2} \\
& 0 \leq \gamma \leq 1
\end{aligned}
$$

where, $\gamma$ parameter gamma shows the share of inefficiency in the overall residual variance and lies between zero and one. If gamma is equal to zero, then it means that all variations of salt production revenue are due to noise and if it is equal to one, then it means that all variations are due to technical inefficiency (Coelli and Battese, 1996). It is worth mentioning here that the above models for the inefficiency effects are stochastic and have a particular distributional specification. Here, it is interesting to test the following hypotheses:

- $\mathrm{H}_{0}: \gamma=\delta_{0}=\ldots=\delta_{10}=0$, i.e., inefficiency is absent

- $\mathrm{H}_{0:} \gamma=0$, i.e., inefficiency effects are not stochastic

- $\mathrm{H}_{0:} \delta_{0}=\ldots=\delta_{10}=0$, i.e., the coefficients of explanatory variables in the models are simultaneously zero

- $\mathrm{H}_{0}: \delta_{1}=\ldots=\delta_{10}=0$, i.e., the coefficients of the variables in the model for inefficiency effects are zero

The tests of these hypotheses for the parameters of the frontier are conducted using the generalized likelihood ratio statistics, $\lambda$ defined as Equation 6:

$\lambda=-2\left[L R_{R}-L R_{U}\right]$

where, $\mathrm{LR}_{\mathrm{R}}$ is the value of the likelihood function for the frontier model in which parameter restrictions are specified by the null hypothesis and $\mathrm{LR}_{\mathrm{U}}$ is the value of the likelihood function for the general linear frontier model. If the null hypothesis is true, then $\lambda$ has approximately a chi-square (or mixed square) distribution with the degrees of freedom equal to the difference between the parameter estimated under $L_{R}$ and $\mathrm{LR}_{\mathrm{U}}$, respectively. The technical efficiency of the salt producer, given the specification of the model, is defined by $\mathrm{TE}_{\mathrm{i}}=\mathrm{E}\left(-\mathrm{U}_{\mathrm{i}}\right)$. Thus, the technical efficiency of the salt producer lies between zero to one and it is inversely related to the inefficiency model. The parameters of the stochastic frontier production function model are estimated by the method of the maximum likelihood using the Econometric Computer Program Frontier Version 4.1 (Coelli and Battese 1996).

\section{RESULTS}

\subsection{Descriptive Statistics of Variables}

Table 1 provides descriptive statistics of variables used in the stochastic production frontier and the inefficiency effect model. The average value of output, revenue from salt production $\left(\mathrm{Y}_{\mathrm{i}}\right)$, is $5.65 \times 10^{7}$ Guinean Franc (GNF). The inputs represent labor cost, equipment 
cost, tarpaulin cost and dimension of basins. The first three inputs are valued per unit basis $(\mathrm{GNF} / \mathrm{kg})$ and the fourth input, the dimension of basin considered as the farm size is expressed in square meters $\left(\mathrm{m}^{2}\right)$. The dimension of basins ranges from 100 to 440 square meters $\left(\mathrm{m}^{2}\right)$ depending on the scale of referred salt production techniques.

In terms of farm specific variables, the mean distance from homestead to campsite $\left(\mathrm{Z}_{1}\right)$ of salt extraction represents $10.25 \mathrm{~km}$. The land rent $\left(\mathrm{Z}_{2}\right)$ used as a dummy variable ( 0 equals to free and 1 equals to rental). Salt Marsh (SM) producers $(61.5 \%)$ rented the site of salt extraction. However, Guinean Saline (GS) representing $38.5 \%$ extracted salt under area controlled by the state without charges. The age of the household head $\left(Z_{3}\right)$ included as a proxy for farming experience to assess the effects of experience on technical inefficiency. Salt operators averaged 46 years old. The gender participation in salt production $\left(Z_{4}\right)$ also used as a dummy variable. The education level $\left(Z_{5}\right)$ measured in terms of schooling years. It remains an indicator of a better level of education represents an advantage as it can form the basis for motivating producers to adopt the improved salt production techniques. Family size $\left(\mathrm{Z}_{6}\right)$ averaged 11.5 members ranging from 5 to 18 persons. This variable is an indicator of family labor availability. The participation of salt producers to activities organized by local and/or international NGOs $\left(\mathrm{Z}_{7}\right)$ considered also dummy variable. This reflects salt producers' access to institutions for training or sensitization such as mangrove protection. Membership in salt production $\left(Z_{8}\right)$ is also considered as a dummy variable $(1=$ membership and 0 $=$ otherwise). The unit price per salt bag $\left(Z_{9}\right)$ depends on the salt production technique which determines the quality of the salt (Balde et al., 2013b). Based on this, its price varies from 200,000 Guinean Franc (GNF) for GS producers to $365,000 \mathrm{GNF}$ for SM producers. The offfarm income and remittance $\left(\mathrm{Z}_{10}\right)$ is considered in monetary value per family size. According to (Balde et al., 2014b); off-farm income is the income earned from regular and casual employment of the household members and remittance represents an amount transferred from absent family members and from relatives living in other cities in Guinea or abroad.

\subsection{Stochastic Frontier Production}

Table 2 presents the estimated coefficients for the frontier model. Both estimates parameters of Ordinary Least Squares (OLS) and Maximum Likelihood Estimate (MLE) methods were used. The MLE method is more representative of the data set for improved salt producers compared to the OLS method. The results of the stochastic frontier production function estimates are shown in Table 2. The production elasticity of improved salt production conducted by salt producers under Guinean Saline (GS) and Salt Marsh (SM) is positive and significant as expected. The labor cost elasticity is positive and highly significant. Hence, the increasing investment by one percent on labor could raise the salt production by $26 \%$ (Table 2 ). Investment in labor could bring a significant improvement in performance of salt production. This implies that investment in labor remains an important contributor to the improvement of technical efficiency in salt production practiced in the Guinean coastal zone. The elasticity of equipment cost presents a negative sign and it's not statistically significant. The tarpaulin cost is significant and its elasticity is negative. This could be explained by the poor quality of the canvas sheet (tarpaulin). Dimension of basins is also positive and statistically significant. This implies that the size of basin contributes to the revenue from salt production.

The overall technical inefficiency effects are evaluated in terms of the parameters associated with $\sigma^{2}$ and $\gamma$ (Arif et al., 2012). The estimate for the variance parameters $\sigma$ is significantly different from zero at one percent level (Table 2). This indicates statistical confirmation of our presumption that there are differences in Technical Efficiency (TE) among the improved salt producers belonging to GS and SM production techniques. The gamma value $(\gamma)$ of the MLEs of stochastic frontier production model is 0.995 (Table 2). This value is statistically significant at the $1 \%$ level, implying that $99.5 \%$ of variability of revenue from salt production are attributed to technical inefficiency in salt production techniques and the rest $(0.5 \%)$ is due to random noises. This also confirms that the application of the stochastic frontier function model is appropriate for this study. Moreover, the presence of technical inefficiency was tested by the Likelihood Ratio (LR) test. The null Hypothesis $\left(\mathrm{H}_{0}\right)$ implies that gamma value is equal to zero. In other words, variations of salt production revenue are due to random noises or stochastic frontier model is inadequate. Alternative Hypothesis $\left(\mathrm{H}_{1}\right)$ implies that gamma value is different from zero or the application of the stochastic frontier model is adequate. LR test has a mixed chi-square $\left(x^{2} R\right)$ distribution with $\mathrm{R}$ equal to restrictions in the model. According to statistic principles, the null Hypothesis $\left(\mathrm{H}_{0}\right)$ will be rejected if LR test is greater than critical chisquare value table. Table 2 shows that LR value is 88.89 and the critical chi-square value $\left(\mathrm{x}^{2}(1 \% \mathrm{R})\right.$ ) is equal to 21.67 (obtained from Kodde and Palm, 1986). As explained above, LR test is greater than critical chisquare value. Therefore, the null Hypothesis $\left(\mathrm{H}_{0}\right)$ is rejected. It means that surveyed salt producers in the study area were not fully technically efficient. 
Table 1. Summary statistics of the study variables for salt production in Guinean coastal of Koba

\begin{tabular}{llllll} 
Variable & Unit & Mean & Std. Dev. & Min. & Max. \\
\hline Salt Production $(S P)$ specific variables & & & & \\
Revenue from $\mathrm{SP}\left(\mathrm{Y}_{\mathrm{i}}\right)$ & $10^{7} \times \mathrm{GNF}$ & 5.65 & 2.61 & 1.46 & 11 \\
Labor cost $\left(\mathrm{X}_{1}\right)$ & $\mathrm{GNF} / \mathrm{kg}$ & 115.52 & 92.95 & 1.11 & 287.03 \\
Equipment cost $\left(\mathrm{X}_{2}\right)$ & $\mathrm{GNF} / \mathrm{kg}$ & 107.1 & 99.05 & 6.6 & 463.83 \\
Dimension of basins $\left(\mathrm{X}_{3}\right)$ & $\mathrm{m}^{2}$ & 252.92 & 97.34 & 100 & 440 \\
Tarpaulin cost $\left(\mathrm{X}_{4}\right)$ & $\mathrm{GNF} / \mathrm{kg}$ & 61.1 & 58.84 & 2.22 & 250 \\
Farm specific variables & & & & & \\
Distance to campsite $\left(\mathrm{Z}_{1}\right)$ & $\mathrm{km}$ & 10.25 & 8.29 & 0.04 & 25 \\
Land rent $(0=$ free $;=$ rental $)\left(\mathrm{Z}_{2}\right)$ & dummy & 0.62 & 0.49 & 0 & 1 \\
Age $\left(\mathrm{Z}_{3}\right)$ & years & 46.2 & 8.71 & 28 & 60 \\
Gender $(1=$ male; $0=$ female $)\left(\mathrm{Z}_{4}\right)$ & dummy & 1.23 & 0.42 & 1 & 2 \\
Education level $\left(\mathrm{Z}_{5}\right)$ & years & 2.92 & 3.22 & 0 & 9 \\
Family size $\left(\mathrm{Z}_{6}\right)$ & persons & 11.48 & 3.96 & 5 & 18 \\
Participation to activities $\left(\mathrm{Z}_{7}\right)$ & dummy & 0.91 & 0.29 & 0 & 1 \\
Membership in $\mathrm{SP}(1=$ yes; $0=\mathrm{no})\left(\mathrm{Z}_{8}\right)$ & Dummy & 0.57 & 0.5 & 0 & 1 \\
Unit price per salt bag $\left(\mathrm{Z}_{9}\right)$ & $\mathrm{GNF}$ & $301,538.50$ & $80,897.91$ & 200,000 & 365,000 \\
Off-farm income and remittance $\left(\mathrm{Z}_{10}\right)$ & GNF/family size & $82,439.25$ & $46,766.15$ & $22,727.27$ & $279,166.70$ \\
\hline
\end{tabular}

Table 2. Parameter estimates of the stochastic frontier analysis

\begin{tabular}{|c|c|c|c|c|c|c|c|}
\hline \multirow[b]{2}{*}{ Variables and parameters } & & \multicolumn{3}{|c|}{ OLS estimates } & \multicolumn{3}{|c|}{ ML estimates } \\
\hline & & Coeff. & Std error & t-ratio & Coeff. & Std error & t-ratio \\
\hline Constant & $\beta_{0}$ & -0.027 & 1.980 & -0.013 & $1.052^{* * *}$ & 0.303 & 3.475 \\
\hline $\ln ($ Labor cost $/ \mathrm{kg})$ & $\beta_{1}$ & $15.673^{* * *}$ & 0.979 & 16.010 & $26.070^{* * * *}$ & 0.840 & 31.027 \\
\hline $\ln ($ Equipment cost $/ \mathrm{kg})$ & $\beta_{2}$ & 0.011 & 0.042 & 0.259 & -0.005 & 0.008 & -0.620 \\
\hline $\ln \left(\right.$ Dimension of basins $\left(\mathrm{m}^{2}\right)$ ) & $\beta_{3}$ & 0.447 & 1.117 & 0.401 & $0.448^{* *}$ & 0.185 & 2.413 \\
\hline ln (Tarpaulin cost $/ \mathrm{kg})$ & $\beta_{4}$ & -0.075 & 0.110 & -0.679 & $0.068^{* * *}$ & 0.021 & -3.246 \\
\hline \multicolumn{8}{|l|}{ Variance parameters } \\
\hline Sigma squared & $\sigma^{2}$ & 7.108 & & & $7.010^{* * *}$ & 1.539 & 4.555 \\
\hline Gamma & $\gamma$ & & & & $0.995^{* * *}$ & 0.005 & 209.795 \\
\hline LR test & & & & & 88.89 & & \\
\hline log likelihood function & & -153.370 & & & -108.926 & & \\
\hline
\end{tabular}

Note: $* * *$ : Significant at $1 \%, * *$ : Significant at $5 \%$

\subsection{Estimation of Technical Inefficiency}

In addition to the analysis of technical efficiency, determinants affecting on technical inefficiency of salt production revenue were estimated. The Maximum Likelihood Estimates (MLEs) for parameters of the technical inefficiency model are presented in Table 3. The estimated coefficients of the explanatory variables in the model for the technical inefficiency effects are of interest and have important implications as revealed in Table 3 .

The impact of distance from the homestead to campsite is negative, but not significant implying that more salt producers are closed to the campsite more technically efficient they are in terms of salt production. The land rent considered as dummy variable is also negative and significant. Salt Marsh
(SM) producers were the only respondents paying rent for land due to salt marshes are under the private ownership. However, Guinean Saline (GS) producers extract salt under area controlled by the state where land rent is not required. With respect to the age of the householder, it is considered as a proxy for farming experience to assess the effects of experience on technical inefficiency. The age coefficient indicated that the younger farmers were more efficient than the older ones (Table 3). This finding confirmed the results of previous studies conducted by (Battese and Coelli, 1995; Mathijs and Vranken, 2000; Bozoglu and Ceyhan, 2007). Gender participation in salt production has a positive sign and significant effect on technical inefficiency in salt production. Also, education level presents an insignificant effect on technical inefficiency. 
The variable of family size is negative and statistically significant. This implies that large family size is technically efficient than small family size. The coefficient of salt producer's participation in activities organized by local and/or international NGOs has a significant effect on technical inefficiency. This participation implies that producers are gaining knowledge and skills in sustainable use of resources for salt production. Another outcome of the inefficiency model was the negative and significant effect of membership in salt production which implied that belonging to a given group of salt production could enhance the technical efficiency of salt producers. This implies that members in salt production are technically efficient than nonmembers. The unit price per salt bag is negative has no significant effect on technical inefficiency (Table 3). The unit price per bag depends on the salt production techniques and determines the quality of the salt (Balde et al., 2013b). The salt produced by the improved techniques was of high quality as it lacked impurities. This study shows that the Off-Farm Income and Remittance (OFIR) per family member is not negative thus, not contributing to technical efficiency.

\subsection{Hypothesis Test}

Tests of null hypotheses associated with the models were carried out using the Likelihood Ratio (LR) statistics and the results are presented in Table 4 . The first null hypothesis, $\mathrm{H}_{0}: \gamma=\delta_{0}=\ldots=\delta_{10}=0$, i.e., that inefficiency is absent from the model, is strongly accepted. This implies that the mean response function is an adequate representation of the data for the improved salt production. The second null hypothesis, $\mathrm{H}_{0}: \gamma=0$, which specifies that the inefficiency effects are not stochastic, is rejected. So, we do not accept the null hypothesis that there was no technical inefficiency. The parameter $\gamma$ is estimated to be 0.995 (Table 2) indicating that $99.5 \%$ of inefficiency is due to the salt producers' own decision and the remaining $0.5 \%$ is due to the factors outside the control of the producers. The parameter $\gamma$ also reflects that the inefficiency effects are highly significant in the analysis of improved salt production.

The third null hypothesis considered in the model, $\mathrm{H}_{0}: \delta_{0}=\ldots=\delta_{10}=0$, i.e., that the coefficients of the explanatory variables in the inefficiency models are simultaneously zero, is accepted. This indicates that all ten explanatory variables considered in the model did not make a significant contribution in the explanation of inefficiency effects associated with the value of output. The last null hypothesis considered, $\mathrm{H}_{0}: \delta_{1}=\ldots=\delta_{10}=$ 0 , i.e., that the coefficients of the variables in the model for inefficiency effects are zero, is also accepted. It reflects that all the coefficients of the explanatory model are not significantly influenced by the following variables: Distance from the homestead to campsite, land rent, age, gender, education, family size, participation in activities organized by local and/or international NGOs, membership in salt production, the unit price per salt bag and off-farm income and remittance per family member.

\subsection{Technical Efficiency Distribution in Salt Production}

The result derived from the ML estimates show Technical Efficiency (TE) indices range from 0.00 to 0.92 with a mean value of 0.27 (Table 5). This means that for an average efficient salt producer to achieve the technical efficiency level of its most efficient counterpart he could realize about (0.92-0.27/0.92) savings in cost or increase in production. This gives about $70.65 \%$ increase in production or cost saving. The least efficient salt producer can now save a cost or increase in production of $100 \%$. (0.92-0.00/0.92) to achieve the required technical efficiency of the most efficient producers in the study sample.

To provide a better indication of the distribution of $\mathrm{TE}$, a frequency distribution of the predicted TE is presented in Table 5.

Among the salt producers $61.54 \%$ are producing at less than $30 \%$ efficiency level while $23.08 \%$ of salt producers have TE of above 0.69 which is an indication that both improved GS and SM salt producers still remain inefficient.

\subsection{Loss Due to Inefficiency and Potential Output}

The potential output as well as loss of output is estimated by dividing the actual output by the mean technical efficiency, whereas the output forgone (loss due to inefficiency) is the difference between the potential output and the actual output (Mor and Sharma, 2012). Table 6 presents an account of the potential as well as the output forgone in improved salt production in the coastal area of Koba in Guinea. These improved salt producers on average loose output worth of 601,024 Guinean francs per basin (GNF/basin) seasonally solely due to the technical inefficiency. This can be regained by way of better utilization of resources which are at the disposal of the salt producers. 
Table 3. Parameter estimates of the technical inefficiency model of salt production

\begin{tabular}{|c|c|c|c|c|}
\hline Variables & Parameters & Coefficient & Std. error & t-ratio \\
\hline Constant & $\left(\delta_{0}\right)$ & $-12.172^{* * *}$ & 3.03600 & -4.008 \\
\hline Distance to campsite $(\mathrm{Km})$ & $\left(\delta_{1}\right)$ & -0.133 & 0.14700 & -0.902 \\
\hline Land rent $(0=$ free; $1=$ rental $)$ & $\left(\delta_{2}\right)$ & $-4.291^{*}$ & 2.42100 & -1.773 \\
\hline Age (years) & $\left(\delta_{3}\right)$ & $5.459^{* *}$ & 2.44800 & 2.230 \\
\hline Gender $(1=$ male; $0=$ female $)$ & $\left(\delta_{4}\right)$ & $0.00024^{* * *}$ & 0.00004 & 5.910 \\
\hline Education level (years) & $\left(\delta_{5}\right)$ & 0.00002 & 0.00001 & 1.611 \\
\hline Family size (number of persons) & $\left(\delta_{6}\right)$ & $-2.625^{* *}$ & 1.30800 & -2.007 \\
\hline Participation in activities $(1=$ Yes; $0=\mathrm{No})$ & $\left(\delta_{7}\right)$ & $-3.658^{* *}$ & 1.80500 & -2.027 \\
\hline Membership in salt production $(1=$ Yes; $0=$ No $)$ & $\left(\delta_{8}\right)$ & $-29.013^{* * *}$ & 6.04900 & -4.796 \\
\hline Unit price per salt bag (GNF) & $\left(\delta_{9}\right)$ & -1.541 & 2.43800 & -0.632 \\
\hline OFIR per family member (GNF/family size) & $\left(\delta_{10}\right)$ & $16.381^{* *}$ & 6.54700 & 2.502 \\
\hline
\end{tabular}

Note: ***: Significant at 1\%, **: Significant at 5\%, *: Significant at 10\% level, OFIR = Off-Farm Income and Remittance

Table 4. Generalized Likelihood Ratio (LR) tests

\begin{tabular}{|c|c|c|c|c|}
\hline Null hypotheses & Log likelihood & $\operatorname{LR}(\lambda)$ & Critical value & Decision \\
\hline $1 . \mathrm{H}_{0}: \gamma=\delta_{0}=\ldots \delta_{10}=0$ & 81.15 & -380.16 & 17.61 & Accept $\mathrm{H}_{0}$ \\
\hline 2. $\mathrm{H}_{0}: \gamma=0$ & -225.40 & 232.94 & 28.86 & Reject $\mathrm{H}_{0}$ \\
\hline 3. $\mathrm{H}_{0}: \delta_{0}=\ldots=\delta_{10}=0$ & 14.86 & -247.58 & 9.50 & Accept $\mathrm{H}_{0}$ \\
\hline 4. $\mathrm{H}_{0}: \delta_{1}=\ldots=\delta_{10}=0$ & 83.35 & -384.56 & 17.61 & Accept $\mathrm{H}_{0}$ \\
\hline
\end{tabular}

Table 5. Frequency distribution of technical efficiency estimates

\begin{tabular}{lcr}
\hline Efficiency level (\%) & No. of salt producers & Percentage \\
\hline$\leq 30$ & 40.00 & 61.54 \\
$30 \sim 39$ & 2.00 & 3.08 \\
$40 \sim 49$ & 3.00 & 4.62 \\
$50 \sim 59$ & 4.00 & 6.15 \\
$60 \sim 69$ & 1.00 & 1.54 \\
$70 \sim 79$ & 8.00 & 12.31 \\
$80 \sim 89$ & 4.00 & 6.15 \\
$90 \sim 99$ & 3.00 & 4.62 \\
Total & 65.00 & 100.00 \\
Mean efficiency & 0.27 & \\
Minimum & 0.00 & \\
Maximum & 0.92 & \\
\hline
\end{tabular}

Table 6. Estimated potential output and output for improved salt production

\begin{tabular}{ll} 
Technical efficiency & Improved salt producers \\
\hline Actual output (GNF/basin) & $222,296.56$ \\
Potential output (GNF/basin) & $823,320.59$ \\
Loss due to inefficiency (GNF/basin) & $601,024.03$ \\
\hline
\end{tabular}

There are three possible ways to increase salt production in the coastal area of Guinea. Firstly, by allocating more land, secondly by developing and adopting new technologies and thirdly by utilizing the available resources more efficiently. The third option of using available resources more efficiently is the most viable approach. This implies that increased salt production hinges upon the improvement of productivity, i.e., yield per unit area. It is generally believed that resources in the agricultural sector, especially in the developing countries are being utilized inefficiently.

\section{DISCUSSION}

As salt production is a major driving force behind the loss of mangrove in Guinea, an understanding of the improved techniques of salt extraction and its efficiency is vital for the mangrove conversation along the Guinean 
coastal area. The measurement of technical efficiency of salt producers adopting the improved salt production techniques was estimated using the stochastic frontier analysis. These improved techniques rely on the sun for energy instead of mangrove wood.

The results of the maximum-likelihood estimates show that labor cost, dimension of basins and cost of tarpaulin are significant but positive for the first two variables. This implies that hiring labors and the size of basins have a crucial role in the performance of salt production in Koba. The hired labor costs mainly include: Digging the canals from which the seawater is channeled to a complex system of reservoirs; levelling the surface of basins. When the levelling is not done properly, it could produce a poor drainage of water to the series of basins. The dimension of basins represents the plot size from where salt is extracted. The negative sign of the tarpaulin or canvas (plastic sheet) reflects its poor quality. Our field investigation revealed that after the evaporation of water from the basins, salt producers collected the crystals by brushing up. This practice easily damages the plastic sheet. Most of salt producers stated that these sheets are very expensive in the open market. Presently, they use sheets provided by NGOs on credit. This credit is settled after the salt harvest in terms of the produce (salt).

As the tarpaulin, the equipment cost has also a negative sign. This demonstrates that the type of materials used with improved salt production techniques in the Guinean coastal area of Koba still remains outdated. For this reason, all stakeholders involved in the salt industry, including the Government Of Guinea (GOG) are required to put more efforts in order to shift from the present so called "improved salt production techniques" to a more efficient level. This strategy will help to conserve natural resources and preserve the environment, while minimizing the environment impact of seawater use.

In addition to the maximum-likelihood estimates of the scholastic frontier, the estimated coefficients of the explanatory variables in the model for the technical inefficiency effects are also of particular interest and have important implications. Interestingly, the dependent variable of the inefficiency model, $\mathrm{u}_{\mathrm{i}}$ from Equation 2, is defined in terms of technical inefficiency; a producerspecific variable associated with the negative (positive) coefficient will have a positive (negative) impact on technical efficiency. Hence, results from Table 3 show that land rent, family size, participation in activities and membership in salt producer organizations are significant determinants of technical efficiency (negative impact on the technical inefficiency). The distance from the homestead to the campsite and the unit price per salt bag were negative but not statistically significant. In contrast, age of the household's head, gender, Off-Farm Income and Remittance (OFIR) per family member and education have positive signs and statistically significant except the variable, education level.

The land rent has a positive and significant effect on the technical efficiency in the improved salt production technique. Salt Marsh (SM) producers were the only respondents paying rent for land due to salt marshes are under the private ownership. However, Guinean Saline (GS) producers extract salt from areas owned by the state where land rent is not required to be paid. Interestingly, the area where land rent is required was far from the sea and no inlets of sea were found around it. This area could be exempt to the flood limiting the processes of the salt production.

The family size has a significant influence on technical efficiency. The implication of this result is that large household size would have positive impact on the efficiency of salt production. This suggests heavy reliance on family labor since family members are expected to provide a significant contribution to the labor force. This finding is in line with Msuya et al. (2008), where it was found that family size has a negative and significant effect on technical inefficiency in maize production.

Participation in the activities initiated by both local and international NGOs has a positive effect on the technical efficiency of salt production. This reflects producers' access to institutions for training or sensitization about the mangrove conservation. The implication of this result is that participants are highly efficient than non-participants. The membership in salt producer organizations has also negative and significant effect on the technical inefficiency (positive and significant effect on the technical efficiency) of salt production. This implies that members in salt production are more efficient than non-members. Both members and non-members in salt producer organizations should be encouraged to participate in activities organized by organizations mentioned above. The focused group conducted during our field investigation found that these members were more informed in terms of the impact of salt production on the mangrove environment. This would be vital if more producer groups are formed to mobilize collective efforts of the producers. Other studies (Balde et al., 2014a) also highlight the importance of membership in the farmers' organization for sustainable agriculture in terms of mitigating land use transition in Dubreka prefecture in Guinea. 


\section{CONCLUSON}

This study measures the technical efficiencies of small-scale improved salt production techniques practiced in the coastal area of Koba in Guinea through the application of stochastic frontier production functions. The production frontiers incorporate labor cost, materials cost (tarpaulin and other equipment) and dimension of basins. Among these inputs, results indicated that only labor cost and dimension of basins contribute to the performance for salt production revenue. There are still rooms for improvement in technical efficiency that can be achieved by salt producers to fully utilize existing resources. Results from the model for the inefficiency effects in the production frontier show that explanatory variables such as land rent, family size; producer's participation in activities and membership in salt production contribute to production efficiency.

Overall, this study revealed a wide variation in the level of technical efficiency of salt producers with an average of $27 \%$. Thus, the salt production in the coastal area of Koba has a potential to be increased by $73 \%$, if prevailing inefficiencies are overcome, without increasing the level of inputs. Furthermore, the loss due to the inefficiency was enormously significant at 601,024 Guinean francs per basin for the whole season of salt extraction. The findings advocate strategies such as encouraging producers' participation in activities organized by local and/or international NGOs for the purpose of sharing knowledge and experience of salt producers, sharing latest information on salt production techniques, being informed about latest government policies and learn to take a balanced approach on salt production and environmental conservation particularly the mangrove ecosystem. This would feasible if more producer groups are formed to mobilize collective efforts of the producers. This study also suggests coating of basins or ponds for limiting the significant loss of salt occurring seasonally. This loss also can be mitigated by improving the quality of tarpaulin (plastic sheet) used.

As with any research, this study too had certain limitations. Studies on the technical efficiency of salt production were not available for the purpose of comparison and discussions with our results. Due to the lack of data related to salt production over the years in the coastal zone of Guinea, this study did not focus on the detail background on salt production in the study area. Since the empirical results are based on relatively limited sample size, the findings should not be overgeneralized. To enhance the generalizability of the results, further scrutiny through theoretical and empirical studies is required. A cross-country comparison of the entire Guinean coastal zone can be made to broaden the usefulness of these results.

\section{REFERENCES}

Aigner, D., C.A.K. Lovell and P. Schmidt, 1977. Formulation and estimation of stochastic frontier production models. J. Econometr., 6: 21-37. DOI: 10.1016/0304-4076(77)90052-5

Arif, A., H. Kabayashi, T. Matsuda, A. Ishida and I. Matsumura et al., 2012. Stochastic frontier approach to measure technical efficiency of two irrigation systems in gilgit district, gilgit-baltistan region of Pakistan. J. Food, Agric. Environ., 10: 543-550.

Bakhsh, K., B. Ahmad and S. Hassan, 2006. Food security through increasing technical efficiency. Asian J. Plant Sci., 5: 970-976.

Balde, B.S., H. Kobayashi, I. Matsumura, M. Nohmi and M. Esham et al., 2013a. Present status and determinants of mangrove rice production in dubreka prefecture in guinea. Japanese J. Farm Manage., 51: 97-102.

Balde, B.S., H. Kobayashi, M. Nohmi, A. Ishida and I. Matsumura et al., 2013b. Socio-economic analysis of small-scale salt production techniques in the coastal area of Guinea: An alternative for improving livelihood status and mangrove forest management. Int. J. Res. Eng., IT Social Sci.

Balde, B.S., H. Kobayashi, I. Matsumura, M. Esham and A. Alam et al., 2014a. Land use changes and their determinants in the coastal area of Guinea: A study based on spatial analysis and field survey. J. Japanese Agric. Syst. Society.

Balde, B.S., H. Kobayashi, A. Ishida, M. Nohmi and M. Esham et al., 2014b. Effects of rural livelihood activities on income inequality and poverty reduction in the guinean coastal area. J. Agric. Sci.

Bamiro, O.M., D.O.A. Phillip and S. Momoh, 2006. Vertical integration and technical efficiency in poultry (Egg) industry in ogun and oyo states, Nigeria. Int. J. Poult. Sci., 5: 1164-1171. DOI: 10.3923/ijps.2006.1164.1171

Battese, G. and T. Coelli, 1995. A model for technical inefficiency effects in a stochastic frontier production function for panel data. Empirical Econom., 20: 325-332. DOI: 10.1007/BF01205442

Binuomote, S.O., J.O. Ajetomobi and A.O. Ajao, 2008. Technical efficiency of poultry egg producers in oyo state of Nigeria. Int. J. Poult. Sci., 7: 1227-1231. DOI: 10.3923/ijps.2008.1227.1231 
Bozoglu, M. and V. Ceyhan, 2007. Measuring the technical efficiency and exploring the inefficiency determinants of vegetable farms in Samsun province, Turkey. Agric. Syst., 94: 649-656. DOI: 10.1016/j.agsy.2007.01.007

Coelli, T., 1996. A guide to FRONTIER version 4.1: A computer program for stochastic frontier production and cost function estimation: CEPA working paper 96/97. Department of Econometrics, University of New England, Armidale, Australia.

Coelli, T. and G. Battese, 1996. Identification of factors which influence the technical inefficiency of Indian farmers. Australian J. Agric. Econom., 40: 103-128. DOI: 10.1111/j.1467-8489.1996.tb00558.x

Coelli, T., D.S.P. Rao and G.E. Battese, 1998. An Introduction to Efficiency and Productivity Analysis. 1st Edn., Springer, New York, ISBN-10: 0387242651, pp: 349.

Ekunwe, P.A., S.I. Orewa and C.O. Emokaro, 2008. Resourse-use efficiency in yam production in delta and Kogi states of Nigeria. Asian J. Agric. Res., 2: 61-69. DOI: 10.3923/ajar.2008.61.69

Kodde, D.A. and F.C. Palm, 1986. Wald criteria for jointly testing equality and inequality restrictions. Econometrica, 54: 1243-1248. DOI: $10.2307 / 1912331$
Mathijs, E. and L. Vranken, 2000. Farm restructuring and efficiency in transition: Evidence from Bulgaria and Hungary. Proceedings of the American Agricultural Economics Association Annual Meeting, Jul. 30-Aug. 2, Tampa, FL, pp: 26-26.

Maadjou, B., 1986. Rapport sur la mise en œuvre du programme sur la biodiversité marine et côtière. Ministry Planning Cooperation.

Mor, S. and S. Sharman, 2012. Technical efficiency and supply chain practices in dairying: The case of India. Agric. Econom. Zemedelska Ekonomika, 58: 85-91.

Msuya, E.E., S. Hisano and T. Nariu, 2008. Explaining productivity variation among smallholder maize farmers in Tanzania. Proceedings of the 8th World Congress of Rural Sociology of the International Rural Sociology Association, (WCR' 08), Goyang, Korea.

Ogundele, F.O and V.O. Okoruwa, 2004. Comparative analysis of technical efficiency between traditional and improved rice variety farmers. African J. Econom. Policy, 11: 91-108. 